\title{
Complete and Partial Responses of the TEMPI Syndrome to Bortezomib
}

\section{Citation}

Schroyens, Wilfried, Casey O'Connell, and David B. Sykes. 2012. “Complete and Partial Responses of the TEMPI Syndrome to Bortezomib." New England Journal of Medicine 367 (8) (August 23): 778-780. doi:10.1056/nejmc1205806.

\section{Published Version}

doi:10.1056/NEJMc1205806

\section{Permanent link}

http://nrs.harvard.edu/urn-3:HUL.InstRepos:37140299

\section{Terms of Use}

This article was downloaded from Harvard University's DASH repository, and is made available under the terms and conditions applicable to Other Posted Material, as set forth at http:// nrs.harvard.edu/urn-3:HUL.InstRepos:dash.current.terms-of-use\#LAA

\section{Share Your Story}

The Harvard community has made this article openly available.

Please share how this access benefits you. Submit a story.

\section{Accessibility}


is one of the very few to have been published. This lack of data on the subject is extraordinary considering the number of fatalities involved. There is an urgent need to study the epidemiologic characteristics related to drowning and the nature of rescue efforts and the management of care after such disasters.

One of the greatest diagnostic challenges is the sudden, unexpected death of a swimmer with no significant medical history and in whom a conventional autopsy is negative. Cardiac channelopathies, particularly those that produce the long-QT syndrome, have been implicated, but they are considered rare. ${ }^{1}$ Nevertheless, such a diagnosis can be of considerable medicolegal and preventive importance. Tester and Ackerman and their colleagues have published studies that have gone a long way toward demonstrating that the cardiac channelopathies are not as rare as originally thought. Their letter is a reminder of the importance of awareness of the problem. The reason why certain mutations are associated with sudden death during swimming, rather than other forms of exercise, remains a mystery. As molec- ular autopsies become more widely available and, it is hoped, cheaper to perform, we may find some answers. ${ }^{2}$ In the meantime, those at risk should receive advice regarding supervised swimming and appropriate cardiac assessment and preventive interventions.

Joost J.L.M. Bierens, M.D., Ph.D.

Society to Rescue People from Drowning

Amsterdam, the Netherlands

Anthony J. Handley, M.D.

Royal Life Saving Society UK

Broom, United Kingdom

James P. Orlowski, M.D.

Florida Hospital

Tampa, FL

Since publication of their article, the authors report no further potential conflict of interest.

1. Lunetta P, Levo A, Laitinen PJ, Fodstad H, Kontula K, Sajantila A. Molecular screening of selected long QT syndrome (LQTS) mutations in 165 consecutive bodies found in water. Int J Legal Med 2003;117:115-7.

2. Tester DJ, Medeiros-Domingo A, Will ML, Ackerman MJ. Unexplained drownings and the cardiac channelopathies: a molecular autopsy series. Mayo Clin Proc 2011;86:941-7.

DOI: 10.1056/NEJMc1207798

\section{Complete and Partial Responses of the TEMPI Syndrome to Bortezomib}

TO THE EDITOR: We recently described the TEMPI syndrome (Aug. 4, 2011), ${ }^{1}$ which is characterized by the pentad of telangiectasias, elevated erythropoietin level and erythrocytosis, monoclonal gammopathy, perinephric fluid collections, and intrapulmonary shunting. One of the patients (Patient 2) had a dramatic response to treatment with the proteasome inhibitor bortezomib, and we hypothesized that the paraprotein may play a role in the pathophysiology of the TEMPI syndrome.

Patient 2, a 48-year-old woman, received a total of eight cycles of intravenous bortezomib (four doses of $1.3 \mathrm{mg}$ per square meter of bodysurface area per cycle). Her telangiectasias disappeared (Fig. 1, Panels A through D), her perinephric fluid collections disappeared (Fig. 1E and $1 \mathrm{~F}$ ), and her serum levels of erythropoietin decreased from $6400 \mathrm{mIU}$ per milliliter to $19 \mathrm{mIU}$ per milliliter. Levels of IgG kappa paraprotein became undetectable. Before treatment, she required a wheelchair and continuous supplemen- tal oxygen; since the completion of treatment, her intrapulmonary shunting has resolved and she has recently resumed jogging. She remains in complete remission 13 months after receiving her last dose of bortezomib.

Patient 3, a 55-year-old woman, received six cycles of intravenous bortezomib. Her telangiectasias resolved, her serum erythropoietin level normalized from a peak of 507 mIU per milliliter, and her partial pressure of oxygen in arterial blood while breathing ambient air improved from $44 \mathrm{~mm} \mathrm{Hg}$ to $70 \mathrm{~mm} \mathrm{Hg}$. Production of perinephric fluid, which drained into her abdomen after surgical fenestration of the renal capsule, decreased, as indicated by a decreasing requirement for large-volume paracentesis. However, after 4 months off treatment, levels of IgG kappa paraprotein began to increase, as did her serum erythropoietin level. Retreatment with bortezomib has been difficult because of the development of severe pulmonary hypertension. 

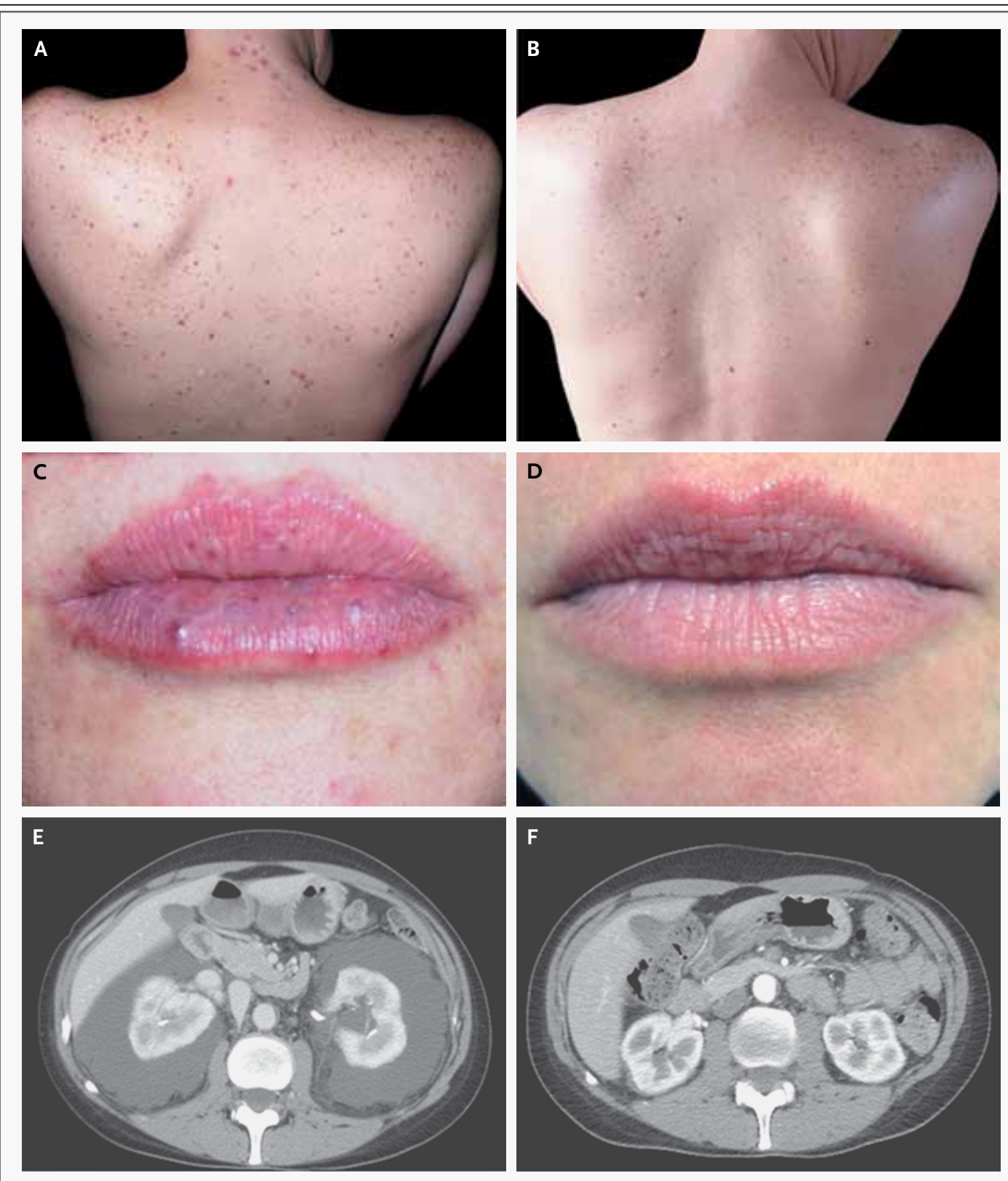

Figure 1. Patient 2, before and after Treatment with Bortezomib.

Photographs taken before and after treatment with bortezomib illustrate the disappearance of telangiectasias from the patient's back (Panels A and B) and lips (Panels C and D). The telangiectasias resolved quite early in the course of treatment and were almost completely gone after the third cycle of bortezomib. The massive perinephric fluid collections in both kidneys completely resolved, as indicated on contrast-enhanced computed tomographic scans of the abdomen (Panels E and F).

Patient 1, a 52-year-old man, has received 9 weekly cycles of intravenous bortezomib. His serum level of erythropoietin has decreased from $5500 \mathrm{mIU}$ per milliliter to $2500 \mathrm{mIU}$ per milliliter; treatment is ongoing. The response to bortezo- mib of another patient with four features of the TEMPI syndrome (there was no intrapulmonary shunting), for whom there was limited follow-up, was recently described in the Journal. ${ }^{2}$

The efficacy of bortezomib treatment, as well 
as the completely reversible nature of the symptoms, suggests that the abnormal plasma-cell clone and monoclonal gammopathy are the likely cause of the TEMPI syndrome. Efforts to identify the antigenic target of the paraprotein are under way. We suspect that there exist other patients with the TEMPI syndrome - as well as patients with other disorders - whose symptoms might be explained by a plasma-cell dyscrasia or underlying monoclonal gammopathy. We welcome any reader insights into this unusual syndrome.

Wilfried Schroyens, M.D., Ph.D.

Antwerp University Hospital

Antwerp, Belgium

Casey O'Connell, M.D.

University of Southern California

Los Angeles, CA

David B. Sykes, M.D., Ph.D.

Massachusetts General Hospital

Boston, MA

dbsykes@partners.org

Disclosure forms provided by the authors are available with the full text of this letter at NEJM.org.

1. Sykes DB, Schroyens W, O'Connell C. The TEMPI syndrome - a novel multisystem disease. N Engl J Med 2011;365:475-7.

2. Kwok M, Korde N, Landgren O. Bortezomib to treat the TEMPI syndrome. N Engl J Med 2012;366:1843-5.

DOI: 10.1056/NEJMc1205806

Correspondence Copyright @ 2012 Massachusetts Medical Society.

INSTRUCTIONS FOR LETTERS TO THE EDITOR

Letters to the Editor are considered for publication, subject to editing and abridgment, provided they do not contain material that has been submitted or published elsewhere. Please note the following:

- Letters in reference to a Journal article must not exceed 175 words (excluding references) and must be received within 3 weeks after publication of the article.

- Letters not related to a Journal article must not exceed 400 words.

- A letter can have no more than five references and one figure or table.

- A letter can be signed by no more than three authors.

- Financial associations or other possible conflicts of interest must be disclosed. Disclosures will be published with the letters. (For authors of Journal articles who are responding to letters, we will only publish new relevant relationships that have developed since publication of the article.)

- Include your full mailing address, telephone number, fax number, and e-mail address with your letter.

- All letters must be submitted at authors.NEJM.org.

Letters that do not adhere to these instructions will not be considered. We will notify you when we have made a decision about possible publication. Letters regarding a recent Journal article may be shared with the authors of that article. We are unable to provide prepublication proofs. Submission of a letter constitutes permission for the Massachusetts Medical Society, its licensees, and its assignees to use it in the Journal's various print and electronic publications and in collections, revisions, and any other form or medium.

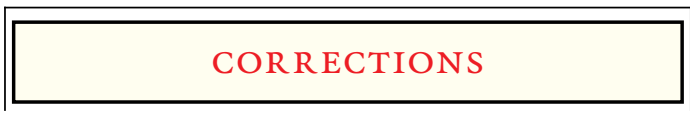

Clinical and Biomarker Changes in Dominantly Inherited Alzheimer's Disease (published Online First at NEJM.org on July 11, 2012; DOI: 10.1056/NEJMoa1202753). In Table 2 (page 5), the parenthetical unit of measure for $\mathrm{A} \beta 42$ in the CSF should have been $\mathrm{pg} / \mathrm{ml}$, rather than $\mathrm{mg} / \mathrm{ml}$. We regret the error. The article is correct at NEJM.org.

A 12-Month Phase 3 Study of Pasireotide in Cushing's Disease (March 8, 2012;366:914-24). In the legend for Figure 1 (page 918), the first sentence should have ended, "50 patients had a substantial reduction (either normalization or $\geq 50 \%$ reduction from baseline) in urinary free cortisol level at month 6 ," rather than " 61 patients had a reduction of at least $50 \%$ in urinary free cortisol levels. . . ." In the first paragraph of the Discussion (page 922), the first sentence should have read, "This randomized, double-blind trial showed that 50 of 103 patients had a substantial reduction (either normalization or $\geq 50 \%$ reduction from baseline) in the urinary free cortisol levels at month 6 . . . " rather than ". . . 61 of 103 patients had a substantial reduction $(\geq 50 \%)$ in the urinary free cortisol level. . . ." Also, several names were misspelled on page 2 of the Supplementary Appendix. The article is correct and the Supplementary Appendix has been replaced at NEJM.org.

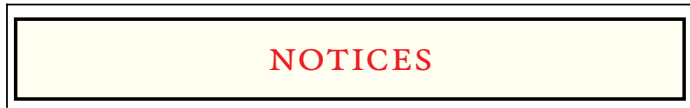

Notices submitted for publication should contain a mailing address and telephone number of a contact person or department. We regret that we are unable to publish all notices received. Notices also appear on the Journal's website (NEJM.org/medical-conference). The listings can be viewed in their entirety or filtered by specialty, location, or month.

\section{INTERNATIONAL SOCIETY FOR INFLUENZA AND OTHER RESPIRATORY VIRUS DISEASES}

The following conferences will be held: "Incidence Severity and Impact" (Munich, Germany, Sept. 5-8) and "Options for the Control of Influenza VIII" (Cape Town, South Africa, Sept. 5-10, 2013).

Contact Integress Meetings and Events, 2 Ravinia Dr., Suite 605, Atlanta, GA 30346; or call (404) 591-3281; or fax (404) 233-2827; or see http://www.controlinfluenza.com.

\section{MEDICAL MUSICAL GROUP}

The symphony orchestra and chorale is seeking participants for its concert entitled "Healing for the Nations," to be presented in Orlando, FL, on Nov. 2 and in Toronto on Nov. 6.

Contact the Medical Musical Group, 1700 17th St. NW, Suite 508, Washington, DC 20009; or call (202) 797-0700; or fax (202) 797-0771; or e-mail vanmmg@hotmail.com; or see http:// www.medicalmusical.org. 